\title{
National and subnational outcomes of waste management policies for 1718 municipalities in Japan: development of a bottom-up waste flow model and its application to a declining population through 2030
}

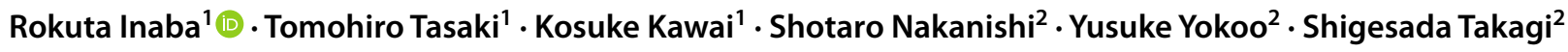

Received: 15 May 2021 / Accepted: 16 September 2021 / Published online: 4 October 2021

(c) The Author(s) 2021

\begin{abstract}
Japan has been promoting $3 \mathrm{R}$ (reduce, reuse, and recycle) policies for several decades, but the recycling rate of the whole country has leveled off, and more effective policies are needed. At the same time, municipalities have been implementing measures for municipal waste management considering their specific regional conditions, but the relationship between the municipalities' policy inputs and national policy output is unclear, which causes difficulties in setting national targets and identifying effective policies. We, therefore, developed the Municipal Input and National Output Waste (MINOWA) model, which represents the municipal waste flows of all 1718 municipalities in Japan. The model enables users to establish various $3 \mathrm{R}$ measures at the municipal level and estimate their effects at the national level. Using the model, we estimated the flows under business-as-usual $(\mathrm{BaU})$ and additional-measure scenarios that extended the use of conventional policies to 2030. The results revealed differences in the policy effects between areas with different populations. In addition, the results showed that the extension of conventional measures will be insufficient to achieve national goals. The developed model links municipal policies, regional characteristics, and national policy and goal-setting in an integrated framework, and supports ways to find more effective policies.
\end{abstract}

Keywords Municipal waste $\cdot$ Scenario analysis $\cdot$ Waste generation $\cdot$ Recycling rate $\cdot$ Local conditions

\section{Introduction}

The European Union announced its action plan for a circular economy in 2015, and efforts aimed at increasing recycling are accelerating around the world. In the EU's revised waste framework directive, numerical targets such as the recycling rate are presented. In general, it has become more important to quantitatively grasp waste flows in each country for quantitative policy making. In Japan, the term "sound material-cycle society" has been used since 2000, and 3R (reduce, reuse, and recycle) policies have been implemented as a means to that end. In addition, material flow indicators such as "resource productivity," "recycling rate," and "final

Rokuta Inaba

inaba.rokuta@nies.go.jp

1 National Institute for Environmental Studies, 16-2 Onogawa, Tsukuba, Ibaraki 305-8506, Japan

2 Mizuho Research \& Technologies, Ltd., 2-3 Kanda-Nishikicho, Chiyoda-ku, Tokyo 101-8443, Japan disposal amount" have been set, and progress towards the formation of a sound material-cycle society has been quantitatively and continuously monitored.

In recent years, Japanese policy progress has leveled off, and additional measures are required. The Japanese national government sets national goals for municipal waste, but each municipality implements specific measures in consideration of local conditions; thus, the national government is not directly involved in the process of planning measures taken by each municipality. The aggregated national achievements of municipal policies on waste reduction and recycling have not been estimated by either national or municipal governments. In addition, the Japanese population is decreasing, and the decrease is distributed unevenly geographically. The amount of waste generated will change from the amount when both the population and amount of waste were increasing. Hence, it is extremely important for the country to estimate waste flows and the outcomes of policies taken by municipalities at the national and subnational levels in the near future in consideration of regional differences. 
Modeling is one approach used to systematically identify solutions to a given problem. According to Morrissey and Browne [1], modeling has been used for waste management since the 1970s, and the first models were used to optimize costs within limited scopes of both time and type of waste management system. However, waste management models have gradually improved and become more sophisticated; and their system boundaries have expanded. In particular, there have been many studies on material flow analysis (MFA) and modeling for waste management. For example, Moriguchi [2] reviewed recent progress in MFA and its use in providing material flow indicators; he also discussed related developments, including developments in Japanese waste-management policy toward reaching a sound material-cycle society. Allesch and Brunner [3] reviewed 83 MFA studies in waste management and stated that MFA is instrumental for understanding how waste management systems function. Sakai et.al [4] also stated that approaches using MFA have become sophisticated enough to describe the fate of resources and hazardous substances based on international workshop including experts and researchers in several countries and a review of 245 previous studies,

At the national level, Starr et al. [5] investigated municipal waste flows in Spain, Italy, and Austria to analyze the potential for biogas production and natural gas substitution. Căilean and Teodosiu [6] compared the sustainability of waste management systems of Romania and the European Union by conducting an MFA. Van Eygen et al. [7] analyzed the material flow of plastic packaging across Austria and compared the environmental impacts of single and composite polymers using inventory analysis data. Eriksen et al. [8] conducted a substance flow analysis and defined indicators such as circularity potential for household waste plastics in Europe while also considering contaminants. However, national analysis and local policies are not directly linked to each other in these studies.

At the municipal level, Vivanco et al. [9] developed a methodology for integrating the material and spatial properties of municipal waste management flows using MFA to develop indicators for bio-waste. They analyzed the Catalunya region of Spain as an example. Turner et al. [10] have developed a method for assessing greenhouse gas (GHG) emissions in a waste management system that combines MFA and life cycle assessment (LCA) methodologies. They conducted an analysis of Cardiff in Wales, compared existing and alternative scenarios, and verified the achievement relative to the recycling target. Langa et al. [11] proposed an integrated industrial analysis for recycling programs based on material and monetary flows to assist local authorities in deciding plans for overall sustainability goals. They then analyzed bio-waste management in Zurich, Switzerland as an example. Gonzalez-Garcia et al. [12] studied urban metabolism as a complex entity driven by the flows of matter and energy as well as resource consumption and waste production, and they developed a multi-criteria approach that combines the methodologies of MFA, LCA, and data envelopment analysis. They applied the approach to 26 representative Spanish cities with different characteristics to identify front runners in waste management. However, they did not conduct an analysis of all cities and municipalities in the country to determine national-level outcomes. In Japan, Matsuto [13] provided the methods to analyze, plan, and evaluate municipal waste treatment systems using MFA and LCA. As far we have been able to determine, no model study has linked the policy inputs of each municipality in a country with the national policy outcomes in an integrated framework while also incorporating regional characteristics.

In this study, we, therefore, developed a municipal waste flow model that estimates the waste flows in all municipalities and evaluates national- and subnational-level outcomes of municipal policies for a better understanding of the linkage between national and municipal policies. We first constructed the model. We then used it to analyze the waste flows of 1718 municipalities in Japan under current conditions and under two future scenarios (through 2030) that incorporate Japan's geographically uneven declining population.

\section{Method}

\section{Outline of the model}

For this study, we developed a bottom-up model-the Municipal Input and National Output Waste (MINOWA) model — using municipality data. The model comprises three sub-models as shown in Fig. 1: household waste, business waste, and waste treatment. Using this model, one can set the extent of policy input and estimate changes in waste flows, such as the waste amount and recycling rate. Each of the sub-models is explained in the following subsections. Details of the model are shown in Appendix 1.

\section{Development of the model}

\section{Household waste sub-model}

The amount of household waste generated in municipality $i$ in year $t, G_{t, i}^{\mathrm{H}}$, is expressed as:

$G_{t, i}^{\mathrm{H}}=\left(1-\alpha_{t, i}^{H}\right) \cdot g_{t, i}^{\mathrm{H}} \cdot P_{t, i}$,

where $\alpha_{t, i}^{\mathrm{H}}$ is the household waste reduction rate achieved through the application of additional measures in 
Fig. 1 Basic structure of the MINOWA (municipal input and national output waste) model

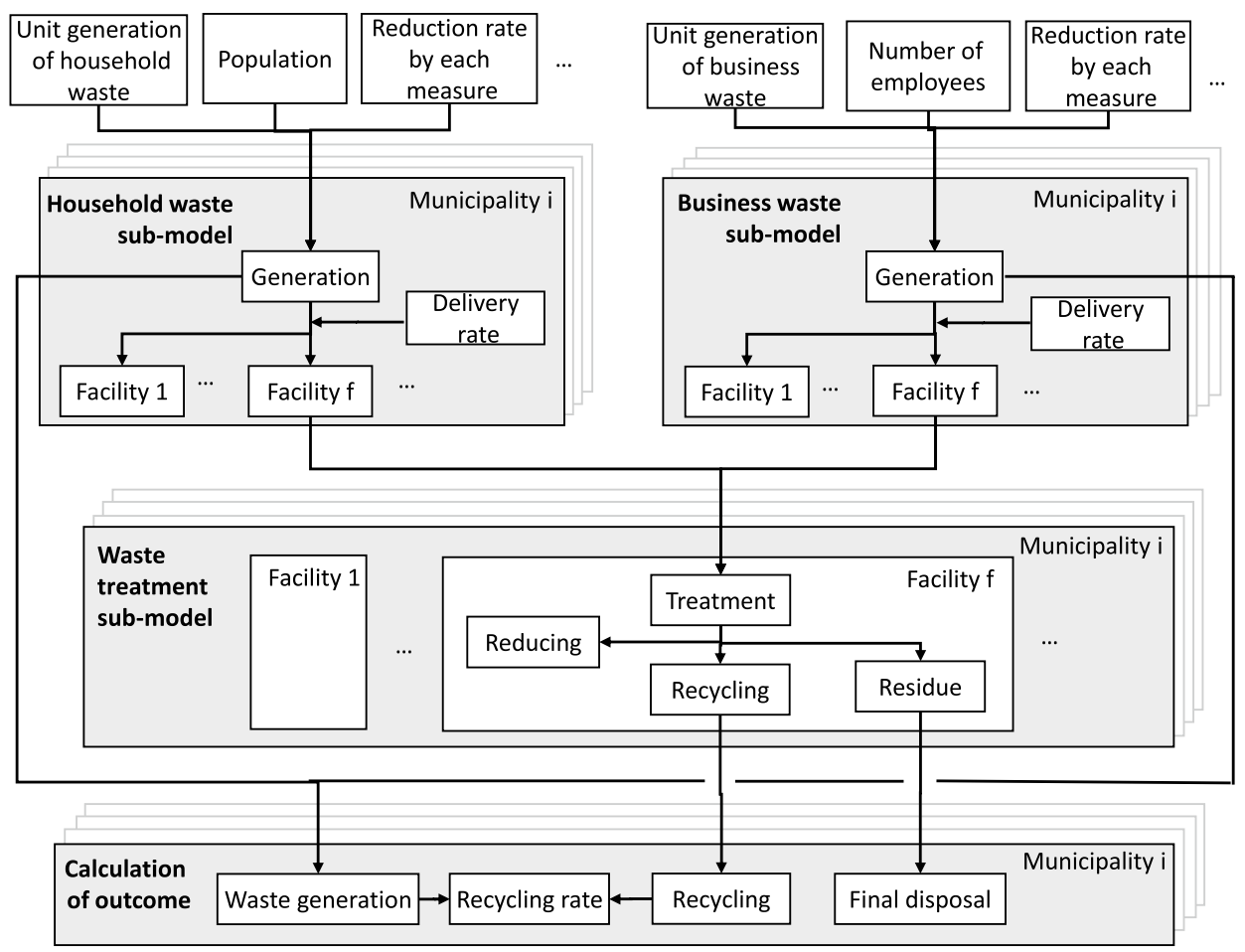

municipality $i$ in year $t$ (year $t_{0}$ is the reference year), $g_{t, i}^{\mathrm{H}}$ is the unit waste generation per population, and $P_{t, i}$ is the population. Additional measures are explained in Sect. Scenario setting. The variables, subscripts, and superscripts used in the equations are also summarized in Table 1.

The collection amount $C_{t, i}^{\mathrm{H}, k}$ and collection rate $c_{t, i}^{\mathrm{H}, k}$ for waste collection method (or destination) $k$ in municipality $i$ in year $t$ are expressed, respectively, as:

$C_{t, i}^{\mathrm{H}, k}=c_{t, i}^{\mathrm{H}, k} \cdot G_{t, i}^{\mathrm{H}}$

$c_{t, i}^{\mathrm{H}, k}=\beta_{t, i}^{\mathrm{H}, k} \cdot \frac{C_{t_{0}, i}^{\mathrm{H}, k}}{G_{t_{0}, i}^{\mathrm{H}}}$,

where $\beta_{t, i}^{\mathrm{H}, k}$ is the rate of change in the collection rate using additional measures, and $G_{t_{0}, i}^{\mathrm{H}}$ is the amount of household waste generation in municipality $i$ in the reference year.

The collection methods $(k)$ consist of citizen-group collection/recycling (CG), municipal collection (MC), and the use of kitchen disposers (DS). The relationship between household waste generation and collection is, therefore, shown as:

$C_{t, i}^{\mathrm{H}, \mathrm{CG}}+C_{t, i}^{\mathrm{H}, \mathrm{MC}}+C_{t, i}^{\mathrm{H}, \mathrm{DS}}=G_{t, i}^{\mathrm{H}}$.
The amount of citizen-group collection is entirely recycled; hence, the amount of household waste recycled by citizen groups in municipality $i$ in year $t, R_{i}^{\mathrm{H}, \mathrm{CG}}$, is expressed as:

$R_{t, i}^{\mathrm{H}, \mathrm{CG}}=C_{t, i}^{\mathrm{H}, \mathrm{CG}}$.

\section{Business waste sub-model}

The amount of waste generated by business activities in municipality $i$ in year $t, G_{t, i}^{\mathrm{B}}$, is expressed as:

$G_{t, i}^{\mathrm{B}}=\left(1-\alpha_{t, i}^{\mathrm{B}}\right) \cdot g_{t, i}^{\mathrm{B}} \cdot W_{t, i}$,

where $\alpha_{t, i}^{\mathrm{B}}$ is the reduction rate of business waste using additional measures, $g_{t, i}^{\mathrm{B}}$ is the unit generation per business worker, and $W_{t, i}$ is the number of workers. Additional measures for business waste are explained in Sect. Scenario setting.

The collection amount $C_{t, i}^{\mathrm{B}, k}$ and collection rate $c_{t, i}^{\mathrm{B}, k}$ of business waste for treatment method $k$ in municipality $i$ in year $t$ are expressed, respectively, as:

$C_{t, i}^{\mathrm{B}, k}=c_{t, i}^{\mathrm{B}, k} \cdot G_{t, i}^{\mathrm{B}}$ 
Table 1 Symbols, subscripts, and superscripts used in the equations in this study

\begin{tabular}{|c|c|c|}
\hline Category & Notation & Name of variable or meaning \\
\hline \multirow[t]{18}{*}{ Symbol } & $G$ & The amount of waste generation \\
\hline & $C$ & The amount of waste collection \\
\hline & $R$ & The amount of waste recycling \\
\hline & $F$ & The amount of final disposal of waste \\
\hline & $T$ & The amount of waste treatment \\
\hline & $S$ & The amount of waste reduced at a facility \\
\hline & $U$ & The amount of residue generated at a facility \\
\hline & $P$ & Population \\
\hline & $W$ & The number of business workers \\
\hline & $g$ & Unit generation of waste per capita or per worker \\
\hline & $c$ & Waste collection rate \\
\hline & $d$ & Delivery rate of the collected wastes to a facility \\
\hline & $u$ & Residue generation rate \\
\hline & $r$ & Recycling rate \\
\hline & $h$ & Final disposal rate \\
\hline & $\alpha$ & Waste reduction rate by additional measures \\
\hline & $\beta$ & Rate of change in collection rate by additional measures \\
\hline & $\gamma$ & Rate of change in delivery rate by additional measures \\
\hline \multirow[t]{15}{*}{ Subscript or superscript } & $H$ & Household \\
\hline & $B$ & Business \\
\hline & $C G$ & Citizen group collection \\
\hline & $M C$ & Municipal collection \\
\hline & $D S$ & Use of kitchen disposer \\
\hline & $D R$ & Direct recycling \\
\hline & $F D$ & Final disposal \\
\hline & $I N$ & Incineration \\
\hline & $B W$ & Bulky waste treatment \\
\hline & $R C$ & Recycling \\
\hline & $t$ & Year \\
\hline & $i$ & Municipality \\
\hline & $k$ & Waste collection method (or destination) \\
\hline & $f$ & Facility \\
\hline & $n$ & Recycling technology \\
\hline
\end{tabular}

$c_{t, i}^{\mathrm{B}, k}=\beta_{t, i}^{\mathrm{B}, k} \cdot \frac{C_{t_{0}, i}^{\mathrm{B}, k}}{G_{t_{0}, i}^{\mathrm{B}}}$,

where $\beta_{t, i}^{\mathrm{B}, k}$ is the rate of change in the collection rate of business waste for collection method (or destination) $k$ in municipality $i$ in year $t$, and $G_{t_{0}, i}^{\mathrm{B}}$ is the amount of business waste in municipality $i$ in the reference year.

The collection methods (or destinations) $(k)$ consist of direct recycling by business operators (DR), direct final disposal by business operators (FD), and municipal collection (MC). The relationship between business waste generation and collection is expressed as:
$C_{t, i}^{\mathrm{B}, \mathrm{DR}}+C_{t, i}^{\mathrm{B}, \mathrm{FD}}+C_{t, i}^{\mathrm{B}, \mathrm{MC}}=G_{t, i}^{\mathrm{B}}$.

The amount of business waste sorted and collected for direct recycling is entirely recycled; hence, the amount of business waste directly recycled in municipality $i$ in year $t, R_{t, i}^{\mathrm{B}, \mathrm{DR}}$, is expressed as:

$R_{t, i}^{\mathrm{B}, \mathrm{DR}}=C_{t, i}^{\mathrm{B}, \mathrm{DR}}$.

Similarly, direct final disposal of business waste in municipality $i$ in year $t, F_{t, i}^{\mathrm{B}, \mathrm{FD}}$, is expressed as:

$F_{t, i}^{\mathrm{B}, \mathrm{FD}}=C_{t, i}^{\mathrm{B}, \mathrm{FD}}$ 


\section{Waste treatment sub-model}

Recycling and waste treatment (referred to together as "treatment") are performed by municipality $i$ for both household and business wastes collected in that municipality $\left(C_{t, i}^{\mathrm{H}, \mathrm{MC}}\right.$ and $C_{t, i}^{\mathrm{B}, \mathrm{MC}}$, respectively) and are calculated from the above two waste generation sub-models. The amount of waste treated at facility $f$ in municipality $i$ in year $t, T_{t, i}^{f}$, and the delivery rate of the collected wastes to facility $f$, $d_{t, i}^{f}$, are expressed, respectively, as:

$T_{t, i}^{f}=d_{t, i}^{f} \cdot\left(C_{t, i}^{\mathrm{H}, \mathrm{MC}}+C_{t, i}^{\mathrm{B}, \mathrm{MC}}\right)$

$d_{t, i}^{f}=\gamma_{t, i}^{f} \cdot \frac{T_{t 0, i}^{f}}{C_{t_{0}, i}^{\mathrm{H}, \mathrm{MC}}+C_{t_{0}, i}^{\mathrm{B}, \mathrm{MC}}}$,

where $\gamma_{t, i}^{f}$ is the rate of change of the delivery rate using additional measures, and $T_{t_{0}, i}^{f}$ is the amount of waste treated in the reference year.

Facilities $(f)$ include those for incineration (IN), bulky waste treatment $(\mathrm{BW})$, recycling $\left(\mathrm{RC}_{n}\right.$, considering different types of recycling facilities/technologies, $n$ ), and final disposal (FD, landfilling in this case). The mass balance between collection and treatment of wastes is expressed as:

$T_{t, i}^{\mathrm{IN}}+T_{t, i}^{\mathrm{BW}}+\sum_{n} T_{t, i}^{\mathrm{RC}}+T_{t, i}^{\mathrm{FD}}=C_{t, i}^{\mathrm{H}, \mathrm{MC}}+C_{t, i}^{\mathrm{B}, \mathrm{MC}}$.

At the facilities, some of the delivered wastes are recycled, some are reduced (e.g., by evaporation of water in composting), and the residue is the final disposal amount. Therefore, the amount of waste recycled at recycling facility $\mathrm{RC}_{n}$ (considering multiple recycling technologies) in municipality $i$ in year $t, R_{t, i}^{\mathrm{RC}_{n}}$, is expressed as:

$R_{t, i}^{\mathrm{RC}_{n}}=T_{t, i}^{\mathrm{RC}_{n}}-\left(S_{t, i}^{\mathrm{RC}_{n}}+U_{t, i}^{\mathrm{RC}_{n}}\right)$,

where $S_{t, i}^{\mathrm{RC}_{n}}$ is the amount of waste reduced and $U_{t, i}^{\mathrm{RC}_{n}}$ is the amount of residue generated from recycling facility $\mathrm{RC}_{n}$.

The amount of residue from other intermediate treatments at facility $f$ in municipality $i$ in year $t$ is expressed as:

$U_{t, i}^{f}=u_{i}^{f} \cdot T_{t, i}^{f}$

$u_{i}^{f}=\frac{U_{t_{0}, i}^{f}}{T_{t_{0}, i}^{f}}$,

where $u_{i}^{f}$ is the residue generation rate, taken as the ratio of the amount of residue to the amount of waste treated in the reference year.
Furthermore, part of the residue from intermediate treatments is recycled (e.g., used as aggregate). Thus, the amount of recycled residue from intermediate disposal at facility $f$ in municipality $i$ in year $t, R_{t, i}^{U f}$, and its recycling rate, $r_{i}^{U f f}$, are expressed, respectively, as:

$R_{t, i}^{U, f}=r_{i}^{U, f} \cdot U_{t, i}^{f}$

$r_{i}^{U, f}=\frac{R_{t_{0}, i}^{U, f}}{U_{t_{0}, i}^{f}}$,

where $R_{t_{0}, i}^{U, f}$ is the amount of residue recycled after intermediate disposal in the reference year.

Similarly, the amount of final disposal of the residue from intermediate treatment facility $f$ in municipality $i$ in year $t$, $F_{t, i}^{U, f}$, and its disposal rate, $h_{t, i}^{U, f}$, are expressed as:

$F_{t, i}^{U, f}=h_{i}^{U, f} \cdot U_{t, i}^{f}$

$h_{i}^{U, f}=\frac{F_{t_{0}, i}^{U, f}}{U_{t_{0}, i}^{f}}$.

\section{Calculation of the outcomes of policies in municipalities and across the nation}

The total amount of municipal waste generated in municipality $i$ in year $t$ is expressed as:

$G_{t, i}=G_{t, i}^{\mathrm{H}}+G_{t, i}^{\mathrm{B}}$

The total amount of all municipal wastes recycled in municipality $i$ in year $t, R_{t, i}$, and total recycling rate, $r_{t, i}$, are expressed, respectively, as:

$R_{t, i}=R_{t, i}^{\mathrm{H}, C G}+R_{t, i}^{\mathrm{B}, \mathrm{DR}}+\sum_{n} R_{t, i}^{\mathrm{RC}{ }_{n}}+\sum_{f} R_{t, i}^{U, f}$

$r_{t, i}=\frac{R_{t, i}}{G_{t, i}}$.

The total amount of all garbage finally disposed in municipality $i$ in year $t, F_{t, i}$, is expressed as:

$F_{t, i}=F_{t, i}^{\mathrm{B}, \mathrm{FD}}+T_{t, i}^{\mathrm{FD}}+\sum_{f} F_{t, i}^{U, f}$.

Thus, municipal waste generation, recycling rate, and final disposal for all of Japan can be calculated, respectively, as:

$G_{t}=\sum_{i} G_{t, i}$ 
$r_{t}=\frac{\sum_{i} R_{t, i}}{\sum_{i} G_{t, i}}$

$F_{t}=\sum_{i} F_{t, i}$

The same variables can be calculated at the municipality level in a similar fashion.

\section{Data used for the model}

For the model described above, we used data from the Survey on the Actual Condition of Municipal Waste Management [14]. We also used data from the National Institute of Population and Social Security Research [15] for future population estimates and data from the Economic Census for Business Activity [16] to estimate the number of future employees.

\section{Scenario setting}

Two scenarios were set and used for the analysis. One was a business-as-usual (BAU) scenario, and the other was a scenario including an additional measure (hereinafter, referred to as the "measure scenario"). In the BaU scenario, the population declines, but per capita generation of waste and other amounts are assumed to be the same as they are in the current situation.

For the measure scenario, additional measures were selected to be implemented through 2030 as shown in Table 2 , and the reduction rate $(\alpha)$, the rate of change in the collection rate $(\beta)$, and the rate of change of the delivery rate $(\gamma)$ (Table 3) were set as explained in Sect. Development of the model Additional measures were assigned to one of three categories: reduction, collection, or recycling. For reduction, four measures were considered. "Charging for waste" introduces garbage fees in municipalities where such fees have not yet been implemented. "Reduction in collection frequency" is a measure to reduce the frequency of collection of most major wastes (e.g., combustible waste) to twice a week in municipalities that currently collect them three or more times a week. "Separation of garbage" is a measure to sort and recycle food waste in rural municipalities that have at least a specified minimum farm area per capita. The relationship between collections and farm area was defined with reference to Kawai [17]. For business waste, "Reduction in waste in municipalities with large waste generation" is a measure to reduce waste in municipalities that generate a large amount of waste in the food retail and restaurant industries.

Table 2 Additional measures and the parameters used in the measure scenario

\begin{tabular}{|c|c|c|c|c|}
\hline Additional measure & & & Parameter & Details \\
\hline \multirow[t]{4}{*}{ Reduction } & \multirow[t]{3}{*}{ Household waste } & Charge for waste & Implementation rate & $\begin{array}{l}\text { Implemented in municipalities } \\
\text { that have not been charging for } \\
\text { waste treatment }\end{array}$ \\
\hline & & Change in collection service & Frequency of collection & $\begin{array}{l}\text { Change the collection frequency } \\
\text { from } \geq 3 \text { times per week at } \\
\text { present to } 2 \text { times }\end{array}$ \\
\hline & & Separation of garbage & Implementation rate & $\begin{array}{l}\text { Implemented in municipalities } \\
\text { that have at least a specified } \\
\text { minimum farming area per } \\
\text { capita [14] }\end{array}$ \\
\hline & Business waste & $\begin{array}{l}\text { Reduction of waste in munici- } \\
\text { palities with large waste } \\
\text { generation }\end{array}$ & $\begin{array}{l}\text { Reduction rate in the food retail } \\
\text { and restaurant industries }\end{array}$ & $\begin{array}{l}\text { Food waste policy progresses in } \\
\text { municipalities with large waste } \\
\text { generation }\end{array}$ \\
\hline \multirow[t]{3}{*}{ Collection } & \multirow[t]{2}{*}{ Household waste } & Introduction of kitchen disposers & $\begin{array}{l}\text { Introduction rate of garbage for } \\
\text { sewage }\end{array}$ & $\begin{array}{l}\text { Introduction of kitchen disposers } \\
\text { to } 50 \% \text { of newly built apart- } \\
\text { ment houses }\end{array}$ \\
\hline & & $\begin{array}{l}\text { Collection of miscellaneous } \\
\text { paper }\end{array}$ & Implementation rate & $\begin{array}{l}\text { Implementation of miscellane- } \\
\text { ous paper collection in highly } \\
\text { populated municipalities }\end{array}$ \\
\hline & Business waste & Plastic collection at stores & Amount of collection & $\begin{array}{l}\text { Collection of plastic waste } \\
\text { at retail stores nationwide } \\
\text { (approximately } 9.2 \mathrm{~kg} \text { per site } \\
\text { per year) }\end{array}$ \\
\hline Treatment/Recycling & Composting & Promotion of composting & $\begin{array}{l}\text { Implementation rate for com- } \\
\text { posting }\end{array}$ & $\begin{array}{l}\text { Increased composting in munici- } \\
\text { palities where composting is } \\
\text { feasible }\end{array}$ \\
\hline
\end{tabular}


Table 3 Parameters used in the scenarios

\begin{tabular}{|c|c|c|c|c|}
\hline \multirow[t]{2}{*}{ Paramete } & & \multirow[t]{2}{*}{ Unit } & \multicolumn{2}{|c|}{$\begin{array}{l}\text { Average value of each munici- } \\
\text { pality }\end{array}$} \\
\hline & & & $\mathrm{BaU}$ scenario & Measure scenario \\
\hline$\alpha^{\mathrm{H}}$ & Reduction rate of household waste & - & 0.00 & 0.05 \\
\hline$\alpha^{\mathrm{B}}$ & Reduction rate of business waste & - & 0.00 & 0.01 \\
\hline$\beta^{\mathrm{H}, \mathrm{CG}}$ & Rate of change in the collection rate of household waste for citizen-group collection & - & 0.99 & 0.98 \\
\hline$\beta^{\mathrm{H}, \mathrm{MC}}$ & Rate of change in the collection rate of household waste for municipal collection & - & 0.99 & 0.98 \\
\hline$\beta^{\mathrm{H}, \mathrm{DS}}$ & Rate of change in the collection rate of household waste for the use of kitchen disposers & - & $*$ & $*$ \\
\hline$\beta^{\mathrm{B}, \mathrm{DR}}$ & $\begin{array}{l}\text { Rate of change in the collection rate of household waste for direct recycling by business } \\
\text { operators }\end{array}$ & - & 0.99 & 0.94 \\
\hline$\beta^{\mathrm{B}, \mathrm{FD}}$ & $\begin{array}{l}\text { Rate of change in the collection rate of household waste for direct final disposal by business } \\
\text { operators }\end{array}$ & - & 0.99 & 0.99 \\
\hline$\beta^{\mathrm{B}, \mathrm{MC}}$ & Rate of change in the collection rate of household waste for municipal collection & & 0.99 & 0.84 \\
\hline$\gamma^{\mathrm{IN}}$ & Rate of change of the delivery rate for incineration & - & 1.0 & 0.9 \\
\hline$\gamma^{\mathrm{BW}}$ & Rate of change of the delivery rate for bulky waste treatment & - & 1.0 & 1.0 \\
\hline$\gamma^{\mathrm{CR}_{\text {compost }}}$ & Rate of change of the delivery rate for composting of garbage & - & 1.0 & 250.3 \\
\hline$\gamma^{\mathrm{CR}_{\mathrm{RDF}}}$ & Rate of change of the delivery rate for RDF production & - & 1.0 & 11.7 \\
\hline$\gamma^{\mathrm{FD}}$ & Rate of change of the delivery rate for final disposal & - & 1.0 & 1.0 \\
\hline
\end{tabular}

*Regarding the use of the kitchen disposers, the rate of change in the collection was not given and the amount of collection was set directly in the measure scenario since the amount of collection in 2015 was 0

For collection, three measures were considered. "Introduction of disposers" is a measure to collect food waste by introducing convenient kitchen disposers to $50 \%$ of newly built apartments in urban areas. "Collection of miscellaneous paper" is a measure to collect miscellaneous paper in the most highly populated municipalities (top 20\%). "Plastic collection at stores" is a nationwide measure for collecting waste plastic at retail stores for recycling. Based on a demonstration project by the Ministry of the Environment, it was assumed that each of 880,000 business establishments nationwide will collect $9.2 \mathrm{~kg}$ of plastics per year.

"Promotion of composting" of household food waste was considered as a recycling measure in municipalities where farm area per capita exceeds a minimum ratio and compost is guaranteed to be used. This measure is related to the "separation of garbage" measure.

The values shown in Table 3 are the average of the values in each municipality. Regarding the rate of change $(\beta)$ in collection rate, since the amount of collection by using the kitchen disposers was 0 in 2015, the amount of collection in the measure scenario is directly set without setting the rate of change. Regarding household waste, in the measure scenario, the rate of change in the collection rate for the municipal collection will decrease slightly due to the increase in the amount by the disposer. The rate of change is less than 1 due to the difference in settings for each municipality. Regarding the rate of change $(\gamma)$ of the delivery rate, the rate for garbage to composting $\left(\gamma^{\mathrm{CR}_{\text {compost }}}\right)$ and the rate for miscellaneous paper to $\mathrm{RDF}$ production $\left(\gamma^{\mathrm{RC} \mathrm{RDF}_{\mathrm{RF}}}\right)$ will increase, and the value related to incineration facilities (IN) will decrease accordingly. The value of $\gamma^{\mathrm{CR}_{\text {compost }} \text { in the measure scenario is }}$ very large, because the delivery rate in 2015 are very small, and the delivery amount in the measure scenario calculated from the agricultural land area is considerably large. The reason why the value of $\gamma^{\mathrm{RC}_{\mathrm{RDF}}}$ is relatively large is the same as that of $\gamma^{C R_{\text {compost. }} \text {. }}$
Table 4 Municipal population segments used for the geographical analysis in this study

\begin{tabular}{llll}
\hline & Population range & $\begin{array}{l}\text { No. of municipalities } \\
(\% \text { of total) }\end{array}$ & Total population (\% of total) \\
\hline Segment 1 & $P_{t, i}<10,000$ & $495(29 \%)$ & $2,481,772(2 \%)$ \\
Segment 2 & $10,000 \leq P_{t, i}<30,000$ & $451(26 \%)$ & $8,273,847(6 \%)$ \\
Segment 3 & $30,000 \leq P_{t, i}<100,000$ & $505(30 \%)$ & $27,754,811(22 \%)$ \\
Segment 4 & $100,000 \leq P_{t, i}<300,000$ & $195(11 \%)$ & $31,636,702(25 \%)$ \\
Segment 5 & $300,000 \leq P_{t, i}$ & $72(4 \%)$ & $57,836,207(45 \%)$ \\
\hline
\end{tabular}




\section{Segments of municipalities for analysis}

All 1718 of Japan's municipalities were analyzed (the 23 wards of Tokyo were counted as one municipality). To highlight geographical characteristics, we split the municipalities into five segments based on population as shown in Table 4, because policymakers often tend to compare waste management policies among municipalities of similar sizes. Municipalities were categorized based on their population in 2015 .

\section{Current situation}

To better understand the results of the future scenarios, we first present the results for 2015 . The geographical distribution of municipal waste generation in 2015 is shown in Appendix 2(a). Many municipalities with an annual generation of 20,000 t or more are located in large cities and coastal areas. Many that generate less than $5000 \mathrm{t}$ are located in inland forested areas and in Hokkaido (the northern island), where agricultural land and pastures are common. Household municipal waste generation is generally considered to be almost proportional to population, but business municipal waste generation is not necessarily proportional to population, because it can be related to the number of employees. The geographical distribution of annual per capita generation ranged from 300 to less than $400 \mathrm{~kg} /$ person in many urban and coastal municipalities

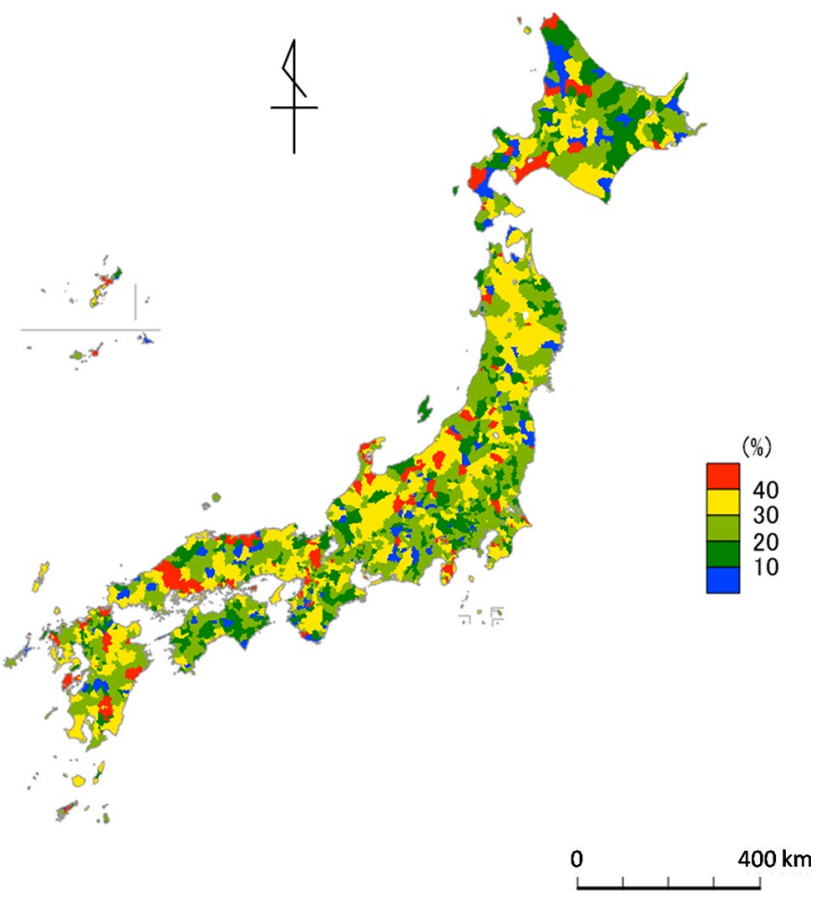

Fig. 2 Business waste percentage in municipal waste generated in 2015 in Japan
(Appendix 2(b)). In inland areas, some municipalities ranged from 200 to less than $300 \mathrm{~kg} /$ person. There were many municipalities with a rate of $400 \mathrm{~kg} /$ person or more in eastern Japan, but few in western Japan. As shown in Fig. 2, the geographical distribution of the percentage of business waste among municipal waste generation was generally $20-30 \%$ in more populous areas, but there were some municipalities that had a rate of at least $40 \%$ in lightly populated areas. These results may reflect the fact that the amount of household waste is large in metropolitan areas because of their large populations, and the amount of business waste derived from tourism is large in some rural areas.

The geographical distribution of the final disposal of municipal waste in 2015 is shown in Appendix 3(a). Here, the final disposal was the sum of the amounts of direct final disposal and final disposal of the incineration residue. Many municipalities in coastal and plain areas had a final disposal amount of $2000 \mathrm{t}$ or more. In Hokkaido, some municipalities in agricultural areas also had amounts of more than $2000 \mathrm{t}$. In terms of annual final disposal amount per capita (Appendix 3(b)), municipalities with less than $25 \mathrm{~kg} /$ person and 25-50 kg/person were common throughout Japan. In central and northern Hokkaido, there were municipalities with rates of at least $100 \mathrm{~kg} /$ person.

The geographical distribution of the recycling rate of municipal waste in 2015 is shown in Appendix 4. Many municipalities throughout the country were in the 10-20\% range, and many rates of at least $20 \%$ tended to be located in inland areas, whereas municipalities with rates exceeding $40 \%$ were mainly located in Hokkaido. As shown in Appendix 5, the share of municipalities with recycling rates below $10 \%$ and greater than $30 \%$ decreased as the population increased, whereas the share of municipalities with recycling rates of $10-20 \%$ increased.

$$
\text { - }<-10 \% \quad-10 \text { to }-5 \% \quad-5 \text { to } 0 \% \quad \geqq 0 \%
$$

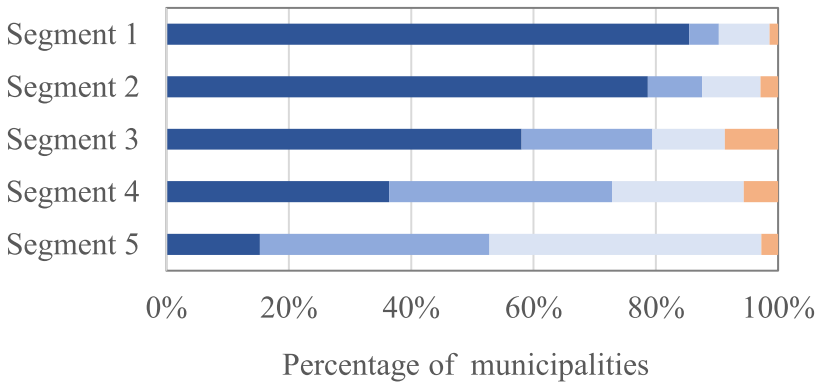

Fig. 3 Differences in municipal waste generation changes from 2015 to 2030 among the five municipal population segments in the $\mathrm{BaU}$ scenario in Japan 


\section{Results and discussion}

\section{Municipal waste flows in the BaU scenario through 2030}

Figure 3 shows predicted changes in waste generation through 2030 in the BaU scenario. In segment 1 (the least populous group), the proportion of municipalities with a reduction of at least $10 \%$ was nearly $85 \%$, but the proportion of municipalities with this reduction rate decreased as the population increased. For example, in segment 5, the proportion of municipalities with a reduction of at least $10 \%$ was only about $15 \%$.

The rates of reduction in segments $1-5$ were $24,20,14$, 12 , and $12 \%$, respectively, and they were caused mainly by population decline. Hashimoto et al. [18] generated scenarios in the near future for waste flow in Japan and predicted its condition. Since the scenarios and flows in their study were for Japan as a whole, the population and the situation of waste management in municipalities were not taken into consideration. Recently, the Ministry of the Environment in Japan commissioned the task of creating a mid- and long-term vision for municipal waste management. A draft version of the vision was publicized by the EX Research Institute [19]. The draft vision discusses predictions of waste generation, but it does not show any geographical differences such as those found in this study.

The rates of change in the final disposal amounts in the BaU scenario are shown in Appendix 6. Reductions in final disposal varied across Japan in 2030. In segment 1, the proportion of municipalities with a reduction of at least $20 \%$ accounted for nearly $60 \%$ of the group. The proportion of municipalities with only a slight decrease in final disposal amount increased as the population increased; for example, in segment $5,80 \%$ or more of the municipalities had a

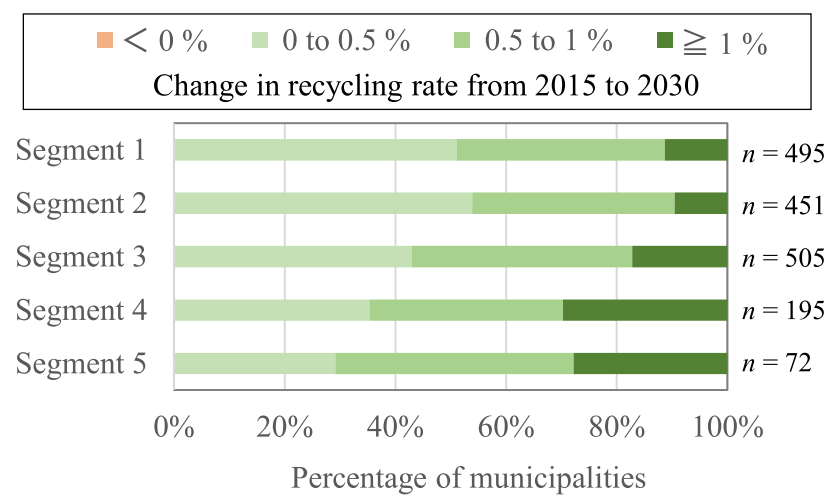

Fig. 4 Differences in recycling rate changes from 2015 to 2030 among the five municipal population segments in the $\mathrm{BaU}$ scenario in Japan reduction rate of less than $10 \%$. The final disposal reduction rates were larger than those of waste generation in corresponding population segments.

The recycling rate in the $\mathrm{BaU}$ scenario was almost unchanged compared to that in 2015 in all population segments (Fig. 4). The proportion of municipalities that increased by $1 \%$ or more in segment 1 was about $10 \%$, and that proportion increased as the population increased; for example, in segment 5 , more than $25 \%$ of municipalities increased by at least $1 \%$. The average rates of change in recycling in the segments $1-5$ were $0.6,0.5,0.6,0.7$, and 0.7 , respectively.

\section{Municipal waste flows in the measure scenario}

Figure 5 shows the rate of reduction of waste generation by population segment for both scenarios in 2030. Waste generation decreased in all segments in both scenarios, but the reduction was greater in the measure scenario in all population segments. In each scenario, the reduction rate was higher in the less populous segments, whereas the increase in the reduction rate in the measure scenario tended to be larger in the more populous segments. Almost $90 \%$ of segment 1 municipalities had at least a $10 \%$ reduction in waste generation in the measure scenario (Appendix 7). The proportion of municipalities with a smaller reduction increased as the population increased. However, this tendency was weaker than it was in the $\mathrm{BaU}$ scenario (Fig. 3), and even in segment 5 , the percentage of municipalities with a reduction of at least $10 \%$ was about $45 \%$. Hence, waste generation was suppressed even in municipalities with large populations. One of the reasons why the reduction rate of the waste generation is larger in the higher populous segment is that the percentage of business waste is relatively large in urban areas, and the reduction measures for municipalities with large waste generation are relatively effective.

The rate of change in final disposal by population segment in the measure scenario is shown in Appendix 8. In segment 1 , nearly $80 \%$ of the municipalities had a decrease

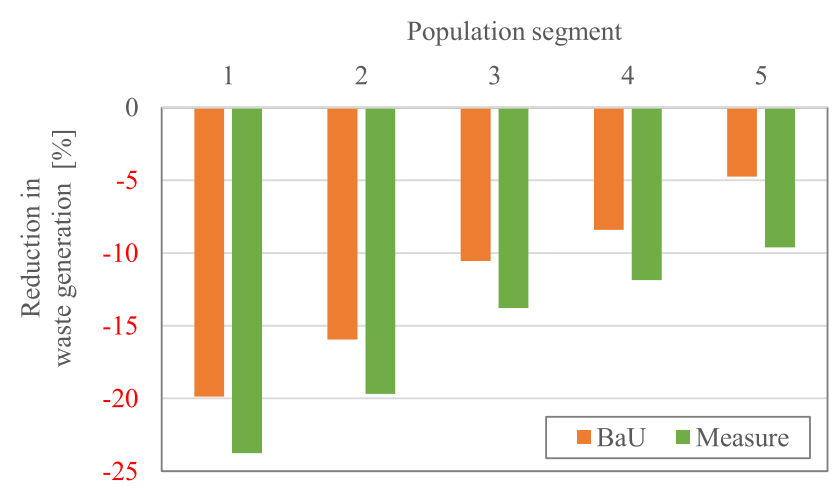

Fig. 5 Reduction in waste generation from 2015 to 2030 by scenario in the five municipal population segments 
of at least $20 \%$. As in the $\mathrm{BaU}$ scenario, the proportion of municipalities with a smaller decrease increased as the population increased. For example, in segment 5 , about $40 \%$ of municipalities had a decrease of less than $10 \%$. Compared to the $\mathrm{BaU}$ scenario (Appendix 6), the rates of decrease in final disposal were larger in all segments in the measure scenario. We aggregated the final disposal amounts for each population category (Appendix 9). The aggregate final disposal amounts decreased from 2015 levels in all segments in both the $\mathrm{BaU}$ and measure scenarios, but the decrease was greater in all segments in the measure scenario.

The recycling rate changes by population segment in the measure scenario are shown in Appendix 10. More than 80\% of municipalities had an increase of $1 \%$ or more from 2015 levels, which is notably higher than the corresponding $10 \%$ value in the $\mathrm{BaU}$ scenario. The change of the recycling rate gradually decreased as population increased, and in segment 5 , only $50 \%$ of municipalities had an increase in the recycling rate of at least $1 \%$. This trend was opposite to that of the $\mathrm{BaU}$ scenario (Fig. 4), but as a whole, the recycling rate increased more in the measure scenario than in the BaU scenario. A small percentage of municipalities' recycling rates actually decreased from the 2015 level; this group was largest in segment 1 and decreased with increased population.

The average recycling rates for each population segment were quite similar in the $\mathrm{BaU}$ scenario and in 2015 (Fig. 6), but they were higher in each segment in the measure scenario. The increase in the measure scenario was larger in

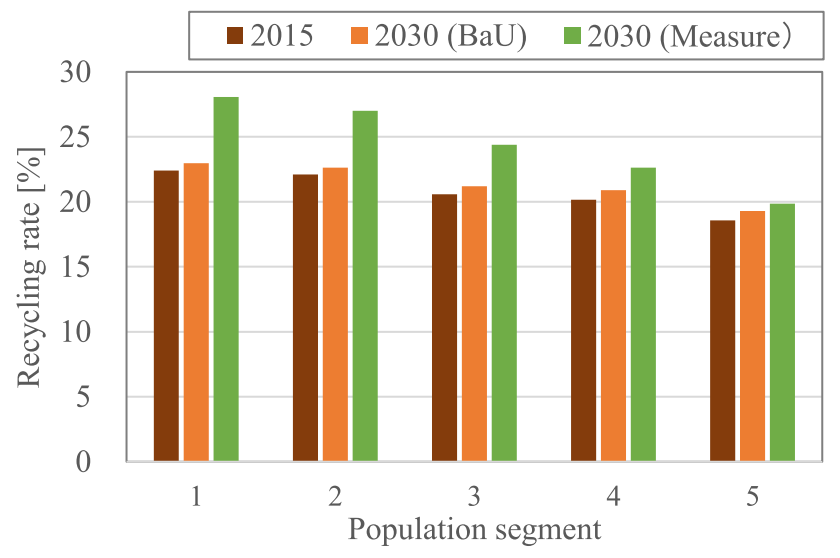

Fig. 6 Average municipal waste recycling rate by scenario and municipal population segment in Japan the smaller population segments. It is thought that one of the reasons for the larger recycling rate in the less populous municipalities is the larger introduction rate of kitchen waste composting derived from the higher ratio of farm area.

\section{Nationwide aggregation of policy outcomes}

Table 5 shows aggregate nationwide municipal waste flows. The aggregate municipal waste generation decreased in the $\mathrm{BaU}$ scenario in 2030 and decreased even more in the measure scenario. The results in the BaU scenario were most likely mainly influenced by the decline in population. The total amounts of final disposal for each municipality followed the same trend, whereas the national recycling rate increased slightly to $20 \%$ in the $\mathrm{BaU}$ scenario and to $22 \%$ in the measure scenario.

The Japanese national government set target values of municipal waste generation of $38,000 \mathrm{kt}$ and final disposal of $3,200 \mathrm{kt}$ in 2025 , but our estimates showed that the aggregate results of municipalities in the $\mathrm{BaU}$ and measure scenarios in 2025 will not achieve these goals. More effort would therefore be required to meet the targets. Based on the results of this study, additional measures in populated areas are strongly recommended, particularly, for plastic waste. However, to identify important specific measures on a reliable basis, we need data on waste composition and robust effectiveness data for strong policy instruments. Acquisition of such data and detailed analyses based on these data remain as future research tasks. The recycling rate target value for 2025 is $28 \%$. Our estimates for the $\mathrm{BaU}$ and measure scenarios in 2025 are $19.6 \%$ and $20.7 \%$, respectively, both of which show slight increases from $19.1 \%$ in 2015 . Therefore, achieving the target recycling goal remains a difficult future task. Realistic goal setting is recommended, and the MINOWA model should be a powerful tool to aid policymakers in Japan.

\section{Conclusion}

In this study, we developed the MINOWA model, which enabled us to analyze the municipal waste flows of 1718 Japanese municipalities and estimate national policy outcomes from municipal-level policy inputs. Using this model, we set a $\mathrm{BaU}$ scenario in which current conditions will be maintained through 2030 and several measure scenarios in which use of
Table 5 Nationwide waste flow indices aggregated from all municipalities in Japan in 2015, 2025, and 2030

\begin{tabular}{|c|c|c|c|c|c|c|c|}
\hline \multirow[t]{2}{*}{ Index } & \multirow[t]{2}{*}{ Unit } & \multirow[t]{2}{*}{2015} & \multicolumn{3}{|l|}{2025} & \multicolumn{2}{|l|}{2030} \\
\hline & & & $\mathrm{BaU}$ & Measure & Target & $\mathrm{BaU}$ & Measure \\
\hline Waste generation & kt/year & 44,022 & 41,947 & 40,091 & 38,000 & 40,562 & 38,765 \\
\hline Final disposal & $\mathrm{kt} / \mathrm{year}$ & 4294 & 4047 & 3839 & 3200 & 3893 & 3676 \\
\hline Recycling rate & $\%$ & 19.1 & 19.6 & 20.7 & 28.0 & 19.8 & 21.5 \\
\hline
\end{tabular}


conventional measures will advance. We then estimated policy outcomes, such as reduced waste generation and increased recycling rates, for the entire country and five population segments. The results showed that the waste reduction measures are more effective in areas with a large population, and the collection/recycling measures are more effective in areas with a small population. According to the nationwide aggregate results, none of the indicators achieved the government's target values for 2025, and the discrepancy was greatest in the recycling rate. More effective measures must be pursued, particularly to meet the target recycling rate, and national goals should be set with consideration of the regional characteristics of each municipality's policies. An example of a more effective measure is the deployment in other regions based on the results of a trial project in a specific region.

This study developed the MINOWA model, which links the policy inputs of municipalities and national policy outcomes in a unified framework, with the goal of supporting more effective policies. The model requires detailed waste data from each municipality, which the Ministry of the Environment of Japan collects; however, many countries lack such detailed data. Establishing detailed waste statistics is an important task for a better linkage between national and municipal policies.

Supplementary Information The online version contains supplementary material available at https://doi.org/10.1007/s10163-021-01303-7.

Acknowledgements This study was supported by the Environment Research and Technology Development Fund (1-1601) of the Environmental Restoration and Conservation Agency.

Open Access This article is licensed under a Creative Commons Attribution 4.0 International License, which permits use, sharing, adaptation, distribution and reproduction in any medium or format, as long as you give appropriate credit to the original author(s) and the source, provide a link to the Creative Commons licence, and indicate if changes were made. The images or other third party material in this article are included in the article's Creative Commons licence, unless indicated otherwise in a credit line to the material. If material is not included in the article's Creative Commons licence and your intended use is not permitted by statutory regulation or exceeds the permitted use, you will need to obtain permission directly from the copyright holder. To view a copy of this licence, visit http://creativecommons.org/licenses/by/4.0/.

\section{References}

1. Morissey A, Browne J (2004) Waste management models and their application to sustainable waste management. Waste Manag 24:297-308

2. Moriguchi Y (2007) Material flow indicators to measure progress toward a sound material-cycle society. J Mater Cycles Waste Manag 9:112-120

3. Allesch A, Brunner P (2015) Material flow analysis as a decision support tool for waste management. J Ind Ecol 19(5):753-764

4. Sakai S, Yano J, Hirai Y, Asari M, Yanagawa R, Matsuda T, Yoshida H, Yamada T, Kajiwara N, Suzuki G, Kunisue T, Takahashi S, Tomoda K, Wuttke J, Mählitz P, Susanne Rotter V,
Grosso M, Fruergaard Astrup T, Cleary J, Oh G, Liu L, Li J, Ma H, Kim Chi N, Moore S (2017) Waste prevention for sustainable resource and waste management. J Mater Cycles Waste Manag 19:1295-1313

5. Starr K, Villalba G, Gabarrell X (2015) Upgraded biogas from municipal solid waste for natural gas substitution and $\mathrm{CO} 2$ reduction - a case study of Austria Italy, and Spain. Waste Manag $38: 105-116$

6. Căilean D, Teodosiu C (2016) An assessment of the Romanian solid waste management system based on sustainable development indicators. Sustain Prod Consum 8:45-56

7. Van Eygen E, Laner D, Fellner J (2018) Environmental assessment of waste management system scenarios: the case of plastic packaging in Austria. Environ Sci Technol 52:10934-10945

8. Eriksen M, Damgaard A, Boldrin A, Astrup T (2018) Quality assessment and circularity potential of recovery systems for household plastic waste. J Ind Ecol 23(1):156-168

9. Vivanco D, Ventosa I, Durany X (2012) Building waste management core indicators through spatial material flow analysis: net recovery and transport intensity indexes. Waste Manag 32:2496-2510

10. Turner D, Williams I, Kemp S (2016) Combined material flow analysis and life cycle assessment as a support tool for solid waste management decision making. J Clean Prod 129:234-248

11. Langa D, Binder C, Stauffacher M, Ziegler C, Schleiss K, Scholz $R$ (2006) Material and money flows as a means for industry analysis of recycling schemes: a case study of regional bio-waste management. Resour Conserv Recy 49:159-190

12. Gonzalez-Garcia S, Manteiga R, Moreira M, Feijoo G (2018) Assessing the sustainability of Spanish cities considering environmental and socio-economic indicators. J Clean Prod 178:599-610

13. Matsuto T (2005) Analysis, planning and evaluation of municipal waste treatment system - material flow and LCA evaluation program. Gihodo Publication co, ltd., Tokyo (in Japanese)

14. Ministry of the Environment, Japan, the survey on the actual condition of municipal waste management. https://www.env.go.jp/ recycle/waste_tech/ippan/stats.html. Accessed 31 Jan 2021 (in Japanese)

15. National Institute of Population and Social Security Research (2014) Regional population projection for Japan: 2010-2040 (March 2013). http://www.ipss.go.jp/pp-shicyoson/e/shicyoson13/ t-page.asp. Accessed 31 Jan 2021 (in Japanese)

16. Ministry of Internal Affairs and Communications, Japan (2017) 2016 Economic census for business activity. https://www.e-stat. go.jp/stat-search/files?page $=1 \&$ layout $=$ datalist $\&$ toukei $=00200$ $553 \&$ tstat $=000001095895 \&$ cycle $=0 \&$ tclas $1=0000011164$ $97 \&$ tclass $2=000001116502 \&$ stat_infid $=000031727909 \&$ tclas $\mathrm{s} 3 \mathrm{val}=0$. Accessed 31 Jan 2021 (in Japanese)

17. Kawai K (2017) Estimation model of recycling rate for municipal waste treatment at the national level based on the garbage composting promotion scenario, proceedings of 28th conference of Japan society of waste management and material cycles, pp 23-24 (in Japanese)

18. Hashimoto S, Osako M, Abe N, Inaba R, Tasaki T, Nansai K, Fujii M, Matsuhashi K, Moriguchi M (2009) Scenarios planning on resource/waste flows and resource recycling/waste management system in the near future. J Jpn Soc Civ Eng Ser G Environ Res 66(1):44-56 (in Japanese)

19. EX Research Institute Ltd. (2021) Report of formulating a vision regarding medium- to long-term municipal waste management. Commissioned by the Ministry of the environment, Japan (in Japanese)

Publisher's Note Springer Nature remains neutral with regard to jurisdictional claims in published maps and institutional affiliations. 